\title{
Evaluation of the reliability and validity of the Early Childhood Oral Health Impact Scale (ECOHIS) questionnaire translated into Malagasy
}

Jeannot Randrianarivony ${ }^{1 *}$, Justin Jacques Ravelomanantsoa ${ }^{1}$ and Noeline Razanamihaja ${ }^{2,3}$

\begin{abstract}
The Early Childhood Oral Health Impact Scale (ECOHIS) was developed to assess the impact of oral health conditions on the quality of life of preschool children and theirs families. The ECOHIS was originally developed in English language, translated and validated in several countries but no validated transcultural version of this questionnaire is currently available in Madagascar. The objectives of this cross-cultural study were to translate, validate and analyse the psychometric properties of the Malagasy version of ECOHIS.
\end{abstract}

Method: The translation followed the forward-backward translation process. The Malagasy version obtained was pre-tested on ten mothers. Then, the questionnaire was administered by interview to 150 parents/guardians of children aged 3 to 5 years old frequenting two nursery schools in the town of Mahajanga to evaluate the reliability and validity of its psychometric characteristics. Reliability was assessed by the test-retest procedure with an interval of 15 days by using the intra-class correlation (ICC). Internal consistency was tested by Cronbach's alpha coefficient. The validity of construct, discriminant and criterion were evaluated. Construct validity was evaluated by Spearman rank correlation and tested using exploratory factor analysis and partial confirmatory factor analysis. Discriminant validity was tested between groups of children presenting consequences of untreated decayed teeth. Clinical examination was performed using the decayed, missing, filled teeth ( $\mathrm{dmft}$ ) and the pulpal involvement, ulceration, fistula, abscess (pufa) indices for assessing dental caries and consequences of untreated decayed teeth.

Results: The cultural adaptation showed that the respondents understood the questions. The intraclass correlation coefficient for test retest was 0.91 . The internal consistency demonstrated a good reliability of the Malagasy-ECOHIS version with a Cronbach's alpha coefficient of 0.88. The convergent validity evaluated by Pearson correlation coefficients provided positive and significant correlation values between all the items ranging from 0.26 to 0.72 . Significant associations between the ECOHIS scores and the global rating of oral health supported the validity of the construct. Convergent and discriminant validity were obtained by testing the association of ECOHIS scores on the child and family sections with poor parental ratings of their child's oral health, high caries experience and untreated decayed teeth consequences which were to be statistically significant.

Conclusion: The results showed that this Malagasy version of ECOHIS questionnaire has shown good psychometric properties and could be used on Malagasy parents of preschool children to measure the impact of oral health status on the child and family quality of life.

Keywords: Preschool child, Oral health, Quality of life, ECOHIS, Validation

\footnotetext{
* Correspondence: jrandrianarivony@yahoo.fr

${ }^{1}$ IOSTM/University of Mahajanga, Mahajanga, Madagascar

Full list of author information is available at the end of the article
}

(c) The Author(s). 2020 Open Access This article is distributed under the terms of the Creative Commons Attribution 4.0 International License (http://creativecommons.org/licenses/by/4.0/), which permits unrestricted use, distribution, and reproduction in any medium, provided you give appropriate credit to the original author(s) and the source, provide a link to the Creative Commons license, and indicate if changes were made. The Creative Commons Public Domain Dedication waiver (http://creativecommons.org/publicdomain/zero/1.0/) applies to the data made available in this article, unless otherwise stated. 


\section{Introduction}

In general, the oral health of individual is evaluated using quantitative clinical indicators such as the such as the decayed, missing, and filled permanent or temporary teeth index (DMFT/dmft) for dental caries and the community periodontal index (CPI/cpi) for periodontal diseases. These indicators measure the presence or the absence of diseases, and their severity and consequences, but not the daily impacts of different oral conditions on an individual's life [1]. In recent decades, new methods of oral health qualitative measures have been developed to evaluate the physical, psychological, and social impact of oral conditions of individuals in the form of standardized questionnaires [2]. These are qualitative measures of subjects' perceptions of positive or negative impact of oral diseases and their treatment on their everyday life established, for example, with the oral health-related quality of life questionnaire (OHRQoL) [3]. Measurement is nowadays considered as an essential element in oral health investigations, especially to determine the repercussions of oral diseases or abnormalities and related treatments on the daily lives of individuals [4]. A large number of measurement instruments have been developed and validated for schoolchildren and adolescents to obtain clinical data on the impact of oral health on their quality of life. They include the Child Perceptions Questionnaire (CPQ) [5-7], the Child Oral Impacts on Daily Performances Index (C-OIDP) [8], the Child Oral Health Impact Profile (COHIP) [9], and the Pediatric Oral Health-Related Quality of Life (POQOL) [10]. Investigations of the repercussions of oral health in young children are lacking due to the absence of paediatric indices to evaluate theses impacts. Furthermore, young children often have cognitive limitations in revealing past events due to their immaturity. However, oral health-related quality of life can be assessed validly and reliably both in self-reports from children as young as 36 months of age and by asking parents/guardians about their perceptions of their child's OHRQoL [11].

Few instruments are available to evaluate the OHRQOL of children aged 0 to 5 years old: the Michigan Oral Health Related Quality of Life scale-child version (MOHRQoL) [11], the Scale of Oral Health Outcomes for 5-year-old children (SOHO-5) [12] the Early Child Oral Health Impact Scale (ECOHIS) [13]. MOHRQoL and ECOHIS were designed only for parental-reporting. ECOHIS is a well-known instrument for assessing oral health quality of life in children aged $0-5$ years old and their families and has been translated into several languages, adapted to different cultures and validated in several countries including France, China, Iran (Farsi), Brazil, India (Urdu) and many others [14-24] but not yet In Madagascar. Such work allows comparing oral health impacts and treatment needs in children at the international level using standardized instruments, and also takes into account their cultural effects. Children under 5 years of age may have many oral health problems, such as teething pains, Early Childhood Caries (ECC) and dental trauma. The ECC is major oral health problem in disadvantaged populations, affects preschool children worldwide and significantly impacts on children's oral health-related quality of life. In Madagascar, $85 \%$ of 6 year-old children have untreated dental caries in primary teeth [25]. There is currently no instrument available in Madagascar to measure the impacts of oral health status on the quality of life of pre-school age children and their families. For this issue, the ECOHIS was chosen in this study. The ECOHIS questionnaire is a parent-assessed OHRQoL. It has been shown capable of capturing the impact of a variety of oral conditions on the quality of life of preschool children and families in several countries. It is acknowledged that before using a measurement instrument in a country, it must be translated and be subjected to cultural adaptation and psychometric property evaluation. The objectives of this cross-cultural study were to translate, validate and analyse the psychometric properties of the Malagasy version of the ECOHIS on children aged 3 to 5 years old.

\section{Methods}

A cross-sectional study was performed in Mahajanga city to test the psychometric characteristics of the Malagasy version of the ECOHIS questionnaire.

The target population was the parents or other adults accompanying young children. The young children were recruited randomly in two public kinder gardens. To be included in the study, the children had to be aged between 3 to 5 years old, and be accompanied by a Malagasy-speaking parent/caregiver. For the parents/ caregiver to be included, they had to be living with the child and be able to speak, read and write Malagasy. The eligible parents $(N=150)$ were informed verbally regarding the objectives of the study and verbal consent was requested. Parents had to self-complete the ECOHIS questionnaire and additional questions on their level of education were asked, The Ethics Committee of the Ministry of Health gave its agreement for the study under number 34-MSANP/CE, on 17 March 2015.

Access to the original questionnaire was possible since it is in an article available through Open Access distributed according to the terms of the Creative Commons Attribute License (http://creativecommons.org/licenses/ by/2.0) of Pahel et al. [13].

\section{Clinical examination}

Before administering the questionnaire, a clinical examination of the preschool children was performed by two dentists familiar with caring for children. The dentists 
were trained to carry out clinical examinations; a calibration test was performed and the statistical Kappa coefficient was 0.87 . The dental caries of primary teeth were recorded according to World Health Organisation (WHO) criteria for the visual evaluation of tooth decay in classrooms, by using mean counts of decayed, missing (due to caries) and filled teeth (dmft) [26]. The PUFA index was used in the clinical examination to record the severity of the consequences of untreated dental decay. The PUFA index records the presence of visible pulpal involvement (p); ulceration caused by dislocated tooth fragments (u), fistula (f), and abscess (a) (PUFA) [27] reported as mean score. The PUFA score per person is calculated cumulatively as DMFT. The children were divided into two groups: group 1(PUFA free) and group 2 with PUFA $\geq 1$.

\section{Cultural and language adaptation}

Translation of the ECOHIS questionnaire into Malagasy In order to use the questionnaire for a population with a different language and socio-cultural context, the original version had to be translated and adapted cross-culturally. The transcultural adaptation was carried out according to international recommendations $[28,29]$. The procedure for evaluating the psychometric properties of a questionnaire consisted of two main steps: a translation phase followed by a phase of reliability and validity evaluation.

The translation phase was structured in 5 steps: forward translation, synthesis by an evaluation committee, back translation, comparison and a pre-test phase.

For the forward translation, two persons, (a dentist familiar with caring for young children and a linguist) translated the original ECOHIS questionnaire into Malagasy independently of each other.

\section{Synthesis}

Once the translations were received, an evaluation committee composed of the two translators, the senior investigator and the authors met and compared the translations from the linguistic, conceptual, practical and cultural angles to finally agree on the 1 st version of ECOHIS in Malagasy.

\section{Back translation}

An English teacher and a certified translator were asked to back translate this 1st Malagasy version into English. These translators were unaware of the existence of the original version.

\section{Comparison}

Once the back-translations were ready, the committee compared them with the original version of ECOHIS in order to discuss possible divergences, evaluate the quality of the translation and obtain a preliminary final version of the questionnaire in Malagasy.

\section{Pre-test and content validity}

This penultimate version was pre-tested for face validity by interviewing the parents (or accompanying adults) of young children aged 3 to 5 years old. The translated questionnaire was self-completed by a sample of 15 parents who spoke, read, and wrote Malagasy perfectly. The pre-test terminated with an open discussion between the respondents and the two interviewers. All the comments expressed by the respondents (questions, words, or sentences that they felt were difficult to understand) were noted and revised by external experts to obtain a final consensual version of the questionnaire. Thus, for instance, instead of the literal translation of the word guilty it was finally decided to use a semantic equivalence: feeling of responsibility or tompon'andraikitra in Malagasy. The pre-test permitted rectifying the imperfections of the first draft of the translated questionnaire. It evaluated the clarity of the questionnaire, the understanding of the words and how the sentences were written. The accuracy items were evaluated during the committee's meetings. The members of the experts committee pursued a discussion approach until consensual agreement was obtained. The final Malagasy version of the ECOHIS questionnaire was then ready for crosscultural evaluation.

\section{Measure}

The ECOHIS is an English language questionnaire. It was developed in the United States to assess the impact of oral health problems and related treatments on the quality of life of preschool children aged 3 to 5 and their families [13]. The scale comprises 13 items, and has two main sections: the Child Impact Section (9 items) and the Family Impact Section (4 items). The Child Impact Section has four domains: child symptom (one item), child function (four items), child psychology (two items) and child self-image and social interaction (two items). The Family Impact Scale has two domains: Parental distress (two items) and Family function (two items). The response options are coded: $0=$ never; $1=$ hardly ever; 2 =occasionally; 3 =often; $4=$ very often. And $I$ don't know response option was also proposed in the American version. Two global rating questions were added at the end of the ECOHIS questionnaire.

\section{Score calculation}

ECOHIS scores were calculated simply as the sum of response codes for the child and family sections separately. The values could range from 0 to 52 for the total scale (0-36 for the child section and $0-16$ for the family 
section). The highest score expressed a higher impact of the state of oral health whereas the lowest score expressed a lower impact. For the domains, the scores were ordered as follows: 0 to 4 for the Child Symptom domain; 0 to 16 for the Function domain (4 items); and 0 to 8 for the last two domains, Psychology and Selfimage. In the Family Impact Section there are two domains containing two items each: Parental distress and Family function and the scores for each domain range from 0 to 8 .

\section{Evaluation of the reliability and validity of the Malagasy version of ECOHIS}

Test-retest reliability was evaluated using an intraclass correlation coefficient (ICC) calculated by a two-way analysis of variance [30]. Thirty parents (2 infants/parents per item was applied, i.e. a minimum of 26 respondents were expected) responded to the items and 2 weeks later they completed the scale a second time. The children were chosen for the stability of their oral health conditions. A period of 2 weeks to 1 month was generally accepted between the test and the retest [31, 32]. An ICC value lower than 0.7 was considered as doubtful reliability; acceptable between 0.7 and 0.8 ; good between 0.8 and 0.9 ; and excellent from 0.9 upwards [30].

Internal consistency was measured by calculating Cronbach's alpha for the child and family sections separately, and for the entire scale. A Cronbach's alpha coefficient higher than 0.70 was considered as reliable [33].

Construct validity is the extent to which an instrument measures the construct that it is intended to measure. Construct validity was achieved when the questionnaire:

1) measured the differences between contrasting groups of participants,

2) reflected the framework hypothesized in a hypothesis testing study, and

3) could undergo a confirmatory factor analysis that adequately establishes that the measurement model fitted the actual data [34].

Thus, the validation of the construct was evaluated by analysing the convergent validity, the factor structure and the discriminant validity.

To determine the convergent validity of the MalagasyECOHIS questionnaire, the parents were asked to answer the two global health-rating questions added at the end of the scale. These subjective self-reported health measures were:

a) In general, how would you rate the dental health of your child?

b) In general, how would you rate the overall health of your child?
The responses options for these questions were scored from 1 to 5 as: $1=$ excellent; $2=$ very good; $3=$ good; $4=$ fair and $5=$ poor. Convergent validity was evaluated based on Spearman's rank order correlation between the scale scores, the scores of the child and family sections and the two global rating questions. Determining the convergent validity consisted in examining the hypothesis, which assumed that parents who declared a high level of impact on the scale would report a poorer state of oral health for the children than parents who declared a low level of impact.

Construct validity was also evaluated by performing exploratory factor analysis using both the principal component analysis with Varimax rotation and Maximum Likelihood with oblique rotation (direct oblimin). Sample adequacy and the appropriateness of the factor analysis were evaluated previously by the Kaiser-Meyer-Olkin (KMO) test and Bartlett's sphericity test. Exploratory Factor Analysis was conducted to extract the new factor structure and examine the construct validity. The number of extracted components was determined by scree plot and the percentage of variance explained by each component. A factor was considered important if its eigenvalue exceeded 1.0 and the significance level was set at $p<0.05$ (two sided) [35]. Model fit was analysed in order to investigate whether the structure of the factors could be reproduced in the Malagasy ECOHIS dataset.

To evaluate the construct validity and confirm the single dimension of the Malagasy version of ECOHIS, a partial confirmatory factor analysis (PCFA) was performed on the 13 items after the exploratory factor analysis. Several model fit indices were used to examine the goodness-of-fit of the model, including the Normed Fit Index (NFI), Comparative Fit Index (CFI), Tucker Lewis Index (TLI) [36] and Root Mean Squared Error of Approximation (RMSEA) [37]. An ideal score of CFI, an NFI $>0.70$, a TLI $>0.90$, and RMSEA scores $<0.10$ were indicative of an acceptable model [38].

An ideal score of CFI, NFI was $>0.70$, TLI was $>0.90$, and RMSEA scores $<0.10$ were indicative of a good model [39].

Regarding discriminant validity, the hypothesis was that the Malagasy version of ECOHIS would be capable of distinguishing pufa-free young children from those with pufa $\geq 1$. Since caries-free preschool children are scarce in the study population, the group who presented $\mathrm{pufa}=0$ were compared with the group with a pufa $\geq 1$. Therefore, the parents of children belonging to the pufa $\geq 1$ group should have a higher ECOHIS score (indicating a poorer oral health-related quality of life) than preschool children with no major oral health problem. The differences were assessed using the Mann Whitney U test. To estimate the effect size, statistics were calculated by dividing the mean ECOHIS scores by the standard 
deviation (SD). The effect size was evaluated by calculating the difference between the means of the ECOHIS total scores for the group with pufa $=0$ and that with pufa $>1$ and dividing the difference by the standard deviation (SD) of the summary scores of the group with pufa $=0$. Effect size statistics of $<0.2$ indicate a small, clinically meaningful magnitude of difference; effect size statistics of 0.2-0.7 indicate a moderate difference, and effect size statistics of $>0.7$ indicate a large difference [40].

Criterion validity Ideally, criterion validity would be measured relative to a gold standard. As no such standard existed for oral health related quality of life measures, and as the criterion had to be a widely accepted measure, a pain item was used for assessing criterion validity. Criterion validity was assessed by comparing the correlation between the total ECOHIS score, subscale scores and the variable pain obtained from the first item of the child impact section, using Spearman's correlation coefficient. Criterion validity was checked by a correlation coefficient. Correlation coefficients equal to 0.70 or over were desirable [41].

Data processing and the statistical analyses were performed using the software Statistical Package for Social Sciences (SPSS) 24.0. The significance levels of the statistical tests were set at 0.05 . According to the authors' recommendations, all the respondents giving the response "I don't know" (DK) to more than 2 items in the parent section and more than 1 item in the infant section should be excluded from the analysis.

\section{Results}

\section{Cultural adaptation and content validity}

The original number of items and domains for the two sections (child impact section and family impact section) were preserved in the Malagasy version. The committee of experts confirmed the relevance of the translated version.

Table 1 presents the socio-demographic characteristics of the children and respondents $(N=150)$. The children were aged from 3 to 5 years old. $78.0 \%$ of the respondents were mothers among whom, 56.7\% had not finished their secondary school, and only 9 had been at high school. The mean (Standard Deviation) DMFT index of the preschool children was 6.01(1.71) Clinical groups were: children with PUFA = $0(n=81)$ and children group with PUFA $\geq 1 \quad(n=69)$.

The Table 2 shows that in this study sample, pain (66.0\%), difficulty eating (54.0\%), trouble sleeping (48.7\%), frustration (48.0\%) and missing school (46.7\%) were the most frequently reported in the Child Impact Section whereas in the Family Section, the impact of financial (63.3\%) and felt guilty (58.0\%), were
Table 1 Demographic characteristic of preschool children and parents respectively

\begin{tabular}{llll}
\hline Demographic characteristic & Frequency & & Mean (SD) \\
& $n$ & $\%$ & \\
\hline Child's characteristics & & & \\
Age & & & \\
3 & 40 & 26.7 & $4.17(0.82)$ \\
4 & 44 & 29.3 & \\
5 & 66 & 44.0 & \\
Gender & & & \\
Boys & 65 & 43.3 \\
Girls & 85 & 56.7 & \\
Parent's characteristics & & \\
Relationship to child & & 78.0 \\
Mother & 117 & 22.0 \\
Father & 33 & \\
Level of education & & 56.7 \\
Unfinished secondary school & 88 & 37.3 \\
Secondary school & 56 & 6.0 \\
High school & 6 &
\end{tabular}

Oral health status $\left(\mathrm{dmft}^{\mathrm{a}}\right)$

$6.01(1.71)$

Clinical groups

Children with

$\begin{array}{lll}\text { pufa }=0 & 81 & 54.00\end{array}$

Children with

pufa $\geq 1$

69

46.00

decayed, missing, filled teeth = dmft; pulp involvement (p), ulceration (u), fistula $(f)$ and abscess $(a)=$ pufa

the most frequently reported. In this evaluation, the Impact on the family was higher (58.2\%) than the impact on the child (51.6\%). Four "Don't Know" (DK) answers were noted in four separate items. No respondent had more than one $D K$ answer. In the Child Impact Section three parents choose $D K$ answer on the items related to pain, to drinking hot and cold beverage and to pronouncing word. In the Family Impact Section, one parent gave $D K$ response option on the item felt guilty.

\section{Reliability}

Test-retest responses revealed an ICC of 0.889. For internal consistency, Cronbach's alpha coefficients test values were 0.807 for the Child impact section, 0.822 for the Family impact section, and 0.847 for the overall Malagasy-ECOHIS score. When the items were deleted one by one, the values did not increase for any of the items. All values of Cronbach's alpha exceeded 
Table 2 Distribution of the Malagasy ECOHIS responses $(n=150)$

\begin{tabular}{|c|c|c|c|}
\hline Impacts & $\begin{array}{l}\text { Never/ hardly } \\
\text { ever } \\
\text { n(\%) }\end{array}$ & $\begin{array}{l}\text { Occasionally/ often /or } \\
\text { very often } \\
n(\%)\end{array}$ & $\begin{array}{l}\text { Don't } \\
\text { know } \\
\mathrm{n}(\%)\end{array}$ \\
\hline \multicolumn{4}{|l|}{ Impact on the Child } \\
\hline \multicolumn{4}{|l|}{ Child symptom } \\
\hline 1. How often has your child had PAIN in the teeth, mouth or jaws & $50(33.3)$ & $99(66.0)$ & $1(0.7)$ \\
\hline \multicolumn{4}{|l|}{ Child function } \\
\hline \multicolumn{4}{|l|}{ How often has your child ...... because of dental problems or dental treatments? } \\
\hline 2. Had difficulty DRINKING hot or cold beverages & $89(59.3)$ & $60(40.0)$ & $1(0.7)$ \\
\hline 3. Had difficulty EATING some foods & 69(46.0) & $81(54.0)$ & $0(0.0)$ \\
\hline 4. Had difficulty PRONOUNCING any words & $84(56.0)$ & $65(43.3)$ & $1(0.7)$ \\
\hline 5. Had missed preschool, day care or school (ABSENCE) & $80(53.3)$ & $70(46.7)$ & $0(0.0)$ \\
\hline \multicolumn{4}{|l|}{ Child psychology } \\
\hline 6. Had trouble SLEEPING & $77(51.3)$ & 73(48.7) & $0(0.0)$ \\
\hline 7. Been irritable or FRUSTRATED & $78(52.0)$ & $72(48.0)$ & $0(0.0)$ \\
\hline \multicolumn{4}{|l|}{ Child self-image and social interaction } \\
\hline 8. Avoided SMILING or LAUGHTHING & $86(57.3)$ & $64(42.7)$ & $0(0.0)$ \\
\hline 9. Avoided TALKING & 110(73.3) & $40(26.7)$ & $0(0.0)$ \\
\hline \multicolumn{4}{|l|}{ Impact on Family } \\
\hline \multicolumn{4}{|l|}{ Parental distress } \\
\hline \multicolumn{4}{|l|}{ How often have you or another family member .... because of dental problems or dental treatments? } \\
\hline 10. Been WORRIED/UPSET & $68(45.3)$ & $82(54.7)$ & $0(0.0)$ \\
\hline 11. Felt GUILTY & $62(41.3)$ & $87(58.0)$ & $1(0.7)$ \\
\hline \multicolumn{4}{|l|}{ Family function } \\
\hline 12. Taken time off from WORK & $65(43.3)$ & $85(56.7)$ & $0(0.0)$ \\
\hline $\begin{array}{l}\text { 13. How often has your child had dental problems or dental treatment that had a financial } \\
\text { impact on your family FINANCIAL }\end{array}$ & $55(36.7)$ & $95(63.3)$ & $0(0.0)$ \\
\hline
\end{tabular}

0.70. The coefficients correlation of corrected items, part of the internal consistency reliability assessment, ranged from $r=0.477$ to $r=0.770$ for child impact section. The lowest coefficients were related to difficulty pronouncing words for the child impact section and felt guilty for the family impact section and the highest values belonged to difficulty eating and taken time off from work for child impact section and family impact section respectively (Table 3 ).

\section{Construct validity}

The correlation between the global ratings (of oral health and overall health) and the ECOHIS total score was found to be statistically, positively significant at $p<$ 0.001 ( $r=0.763$ and $r=0.694$, respectively). Table 4 also shows that the ECOHIS total scores and scores for both ECOHIS sections were significantly, positively related to the parents' global ratings of their children's oral health ( $r=0.763 ; r=0.781 ; r=0.494 p<0.001$, respectively) and overall health $(r=0$. 694; $r=0.760$ and $r=0.378 p<$ 0.001 , respectively).

\section{Factor analysis}

The Bartlett's test of sphericity was significant (where khi2 $=707.983$ for a degree of freedom $(\mathrm{df})=78$ and $\mathrm{p}<$ 0.001). This indicated that the items of the MalagasyECOHIS version were correlated. A KMO index of 0.864 indicated the adequacy of the sampling and thus an exploratory factor analysis could be conducted.

The exploratory factor analysis extracted three main factors with Eigenvalues $>1$ and combined; they were capable of explaining $65.21 \%$ of the variances of which the first factor taken alone explained $46.52 \%$.

\section{First factor}

Child oral health, function and socio- environmental impact, comprised $7 / 9$ items of the Child impact section (items, 1, 2, 3, 5, 6, 7, 9).

\section{Second Factor}

Family emotional and social impact grouped $3 / 4$ items of the Family impact section $(10,11,12)$. 
Table 3 Cronbach's alpha coefficient for child impact section and family impact section assessed separately

\begin{tabular}{|c|c|c|}
\hline & Complete Correlation of corrected items & Cronbach's alpha if item deleted \\
\hline \multicolumn{3}{|l|}{ Child Impact Section } \\
\hline 1 Oral/dental pain & .669 & .839 \\
\hline 2.Difficulty in drinking & .653 & .841 \\
\hline 3.Difficulty in eating & .707 & .839 \\
\hline 4.Difficulty in pronouncing words & .595 & .841 \\
\hline 5.Missed pre-school/school & .655 & .841 \\
\hline 6.Difficulty in sleeping & .707 & .840 \\
\hline 7.Irritable or frustrated & .770 & .837 \\
\hline 8.Avoided smiling or laughing & .703 & .840 \\
\hline 9.Avoided talking & .722 & .842 \\
\hline \multicolumn{3}{|l|}{ Family Impact Section } \\
\hline 10.Been upset & .618 & .840 \\
\hline 11.Felt guilty & .477 & .843 \\
\hline 12.Work & .637 & .841 \\
\hline 13.Financial & .614 & .842 \\
\hline ECOHIS total scale & .847 & \\
\hline
\end{tabular}

\section{Third Factor}

Social Well-being contained three items (items 4, 8, 13) (Table 5).

\section{Partial confirmatory factor analysis (PCFA)}

The Maximum Likehood Estimation (MLA) associated with PCFA solution was equal to 80,874 with 42 degrees of freedom and a $p$ value $<0.001$ which was smaller than the corresponding null model khi2 of Bartlett's test of sphericity. Based on these two khi2 values, the model-fit indices were calculated to be $\mathrm{NFI}=0.88, \mathrm{TLI}=0.88$, $\mathrm{CFI}=0.93$, and RMSEA $=0.07$.

The Visual Summaries of Fit of distributions of the residuals showed that the frequency distributions of the correlation residuals or covariance residuals had a normal shape.

\section{Discriminant validity}

In the two sections of ECOHIS (child impact and family impact), the mean scores were significantly higher in the group of preschool children with mean PUFA count $\geq 1$ compared to the group with PUFA $=0 \quad(p<0.001)$ (Table 6), The effect size was $>0.70$ for the total scale

Table 4 Criterion validity

\begin{tabular}{lll}
\hline ECOHIS & Pain & \\
\cline { 2 - 3 } & $r$ & .000 \\
\hline Total scale & .611 & .000 \\
Child impact section & .624 & .000 \\
Family impact section & .400 & .400 \\
\hline
\end{tabular}

$r$-Spearman correlation coefficient; $p$ value scores, which indicated a moderate to large difference (child impact section)."

\section{Criterion validity}

The relationships between ECOHIS total score and subscales (Child impact and Family impact), and pain as criterion measure were significantly correlated, with Spearman's rank correlation coefficients of $r=0.61 ; r=$ $0.62 ; r=0.40$ respectively (Table 7 ).

Table 5 Construct validity: rank correlations between total scale and subscales scores, and global ratings of oral health and overall health $(n=150)$

\begin{tabular}{|c|c|c|c|c|}
\hline \multirow[t]{3}{*}{ ECOHIS } & \multicolumn{4}{|c|}{ Global ratings of } \\
\hline & \multicolumn{2}{|c|}{ Oral health } & \multicolumn{2}{|c|}{ Overall health } \\
\hline & $r$ & $p$-value & $r$ & $p$-value \\
\hline Total scale & .763 & 0.000 & .694 & 0.000 \\
\hline Child impact section & .781 & 0.000 & .760 & 0.000 \\
\hline \multicolumn{5}{|l|}{ Subscales } \\
\hline Symptom & .554 & 0.000 & .527 & 0.000 \\
\hline Function & .650 & 0.000 & .613 & 0.000 \\
\hline Psychology & .468 & 0.000 & .510 & 0.000 \\
\hline Self-image & .467 & 0.000 & .509 & 0.000 \\
\hline Family impact section & .494 & 0.000 & .378 & 0.000 \\
\hline Parental distress & .445 & 0.000 & .344 & 0.000 \\
\hline Family function & .502 & 0.000 & .380 & 0.000 \\
\hline
\end{tabular}


Table 6 Factor analysis

\begin{tabular}{|c|c|c|c|c|}
\hline \multirow[t]{2}{*}{ Item $N^{\circ}$} & \multirow[t]{2}{*}{ Item } & \multirow{2}{*}{$\begin{array}{l}\text { Factor } 1 \\
\text { Child oral health: function and } \\
\text { socio- environmental impact }\end{array}$} & \multirow{2}{*}{$\begin{array}{l}\text { Factor } 2 \\
\text { Family emotional and } \\
\text { social impact }\end{array}$} & \multirow{2}{*}{$\begin{array}{l}\text { Factor } 3 \\
\text { Social Well-being }\end{array}$} \\
\hline & & & & \\
\hline 1 & Pain & .745 & & \\
\hline 2 & Drinking hot/cold & .679 & & \\
\hline 3 & Eating some foods & .605 & & \\
\hline 4 & Difficulty pronouncing & & & .799 \\
\hline 5 & Missed preschool & .773 & & \\
\hline 6 & Trouble sleeping & .740 & & \\
\hline 7 & Irritable, frustrated & .767 & & \\
\hline 8 & Avoid smiling & & & .658 \\
\hline 9 & Avoid talking & .591 & & \\
\hline 10 & Been upset & & .702 & \\
\hline 11 & Felt guilty & & .775 & \\
\hline 12 & Taken time & & .691 & \\
\hline 13 & Financial impact & & & .596 \\
\hline$\%$ variance explained (total $=65.216 \%$ ) & & 46.524 & 10.789 & 7.903 \\
\hline
\end{tabular}

Varimax rotation with Kaiser normalisation; extraction method: analysis of principal components

\section{Discussion}

The aim of this study was to evaluate the psychometric properties of the Malagasy version of the ECOHIS questionnaire by examining its content, internal consistency, test-retest reliability, convergent, construct, discriminant validity, and criterion validity.

Few instruments have been developed to assess the quality of life for preschool children below the age of 6 years old. ECOHIS is one of the most frequently used questionnaires used to determine such quality of life. The difference between existing measures was that ECOHIS information on the OHRQoL of preschool children was obtained only through parental reports. This was the main raison why we chose the ECOHIS questionnaire. It was important that the parents' perceptions of the impact of oral and dental conditions on the child's and family's daily life were assessed. The resulting scale was obtained from the first OHRQoL questionnaire for preschool children evaluated for Madagascar. In the present study, the cross-cultural adaptation of the Malagasy version of ECOHIS was based on international recommendations $[28,29]$. The result of the forwardbackward translation process showed wordings similar to the original ECOHIS. During the translation phase, we pre-tested the questionnaire to identify misunderstandings of questions. Face and content validity were determined. The results demonstrated that all the items were understood and accepted by the respondents during the pre-test. This procedure was imperative for the cross-cultural and social adaptation of the tool for measuring oral health-related quality of life. For the main study, 150 parents were included. The sample size might be criticised for being small but according to Clark et al., a sample size between 100 to 200 can be considered acceptable [42]. In general, a ratio of 5-10 subjects to 1 item has also been recommended [43]. In addition, according to the quality criteria required to measure the characteristics of the questionnaire on health suggested by Terwee et al., at least 50 subjects were necessary to evaluate the construct validity and the reproducibility analysis, and at least 100 subjects were required to analyse internal consistency [40]. The distribution of the

Table 7 Discriminant validity: overall and subscale scores for parents of children pufa free and children with pufa $\geq 1$

\begin{tabular}{|c|c|c|c|c|c|c|}
\hline \multirow[t]{3}{*}{ ECOHIS } & \multicolumn{4}{|c|}{ Clinical groups } & \multirow{3}{*}{$p$-value } & \multirow{3}{*}{ Effect size } \\
\hline & \multicolumn{2}{|c|}{ Pufa $=0$} & \multicolumn{2}{|l|}{ Pufa $\geq 1$} & & \\
\hline & Mean (SD) & Median & Mean (SD) & Median & & \\
\hline Total scale & 13.53(8.71) & 12 & 20.88(9.63) & 21 & 0.000 & 0.84 \\
\hline Child impact section & $7.86(5.83)$ & 6 & $13.77(6.00)$ & 15 & 0.000 & 1.01 \\
\hline Family impact section & $5.67(3.84)$ & 6 & $7.12(3.71)$ & 8 & 0.020 & 0.37 \\
\hline
\end{tabular}

Standard Deviation (SD) *Mann Whitney test 
responses to all the items showed that in our study, the highest mean scores were obtained in the domains of symptom (pain) and function (eating difficulties, sleeping disorders, irritation or frustration, and missing school). They were the impacts most frequently reported by the parents. These findings were consistent with the studies conducted in France, Brazil, and Lithuania, and with the original questionnaire $[13,14,18,20]$. However, the strong impact of the item "finance" for the family impact section appeared specific to this study. This financial difficulty could explain the high prevalence of decayed teeth remaining untreated reported in the results. The impact of socio economical status on the oral health related quality of life was largely reported in the literature. The authors found that a low socio economical status (SES) could negatively affect the oral health related quality of life of children [44]. In the present study, reliability assessed by both the test-retest and internal consistency was satisfactory. Values were higher than 0.70 , in line with what was demonstrated by all the previous versions $[13,14,17,18]$. The test-retest score of 0.88 was consistent with the findings of the original study of ECOHIS (0.84), and the Farsi (0.82), Urdu (0.80) and Chinese $(0.64)$ versions $[13,15,18,24]$. These results showed a good level of agreement between the test and the retest data and reflected the good reliability of the Malagasy ECOHIS version. In order to evaluate the Construct validity, the global ratings of children's overall health and oral health status perceived by parents were correlated with the ECOHIS total scale and subscales. The results showed that global ratings of oral health and overall health were significantly and positively correlated to the ECOHIS scale and subscales. Similar findings were reported by the other studies where parents who perceived worse oral health status had significantly higher ECOHIS scores $[13-15,17,19]$.

Moreover, the factor analysis model suggested threefactor models with adequate goodness-of-fit indicators. The exploratory factor analysis revealed three-factor structures instead of two sections with six domains, as in the original version [13] To discuss the model fit of CFA, it has been suggested that a RMSEA value less than 0.08 is good [45]. Therefore, the RMSEA value of 0.07 in this study sample indicated an acceptable fit. The NFI and TLI index values of 0.885 should both be over 0.90 for a good fit, but in this sample the two indices are below this threshold. The CFI of 0.938 was above 0.90 , which showed a good fit. Based on these indices, the sample had an acceptable fit to the 3-factor model. The Malagasy version of ECOHIS was also able to discriminate between children who presented clinical consequences of untreated decayed teeth and those without consequences, measured by the pufa index. The original ECOHIS questionnaire was judged reliable and capable of distinguishing children with different levels of tooth decay [13]. To sum up, in the construct, convergent, concurrent and discriminant validity tests, the analysis showed that the validity of the Malagasy version of ECOHIS is acceptable. Overall tests used to assess the reliability and validity of ECOHIS showed acceptable performance. Although acceptable, the results of the factor analysis were liable to criticism since the sample had fewer than 300 subjects. Indeed, some authors recommended at least 300 subjects to perform a factor analysis [42]. Tabachnick \& Fidell (2007) reported that a ratio of 10 participants per item is sufficient for an exploratory principal component/factor analysis [46]. Since ECOHIS has 13 items, a minimum sample size of 130, therefore, appears suitable to perform an exploratory factor analysis. For Guadagnoli and Velicer, a sample of 150 observations is enough to obtain an adequate solution in a factor analysis as long as the inter-correlations are reasonably strong [47].

\section{Limitations, directions for future research}

Although this study demonstrated that the Malagasy version of ECOHIS obtained good reliability and validity results, other studies should be performed to confirm these characteristics on patients for use in clinical research. Furthermore, other investigations should be carried out to evaluate the reactivity of this version of the ECOHIS questionnaire. The sample was not representative of all preschool children in Madagascar, thus the results cannot be generalized. This Malagasy version of ECOHIS should be tested further on other different populations with different clinical diseases to determine its discriminant properties in other clinical situations. This cross-sectional study did not allow measuring the responsiveness of the instrument. A longitudinal study should be conducted in the future.

\section{Conclusion}

Globally, this Malagasy version of the ECOHIS questionnaire can be considered to have good psychometric properties and could be used on the Malagasy parents of preschool children to measure the impact of oral health status on child and family quality of life.

\footnotetext{
Abbreviations

CFI: Comparative Fit Index; COHIP: Child Oral Health Impact Profile; COIDP: Child Oral Impacts on Daily Performances Index; CPQ: Child

Perceptions Questionnaire; DMFT index: Decayed, missing (due to caries) and filled teeth; ECC: Early Childhood Caries; ECOHIS: Early Child Oral Health Impact Scale; ICC: Intraclass Correlation coefficient; MOHRQoL: Michigan Oral Health Related Quality of Life; NFI: Normed Fit Index; OHRQoL: Oral HealthRelated Quality of Life questionnaire; PCFA: Partial Confirmatory Factor Analysis; POQOL: Paediatric Oral Health-Related Quality of Life; PUFA index: Pulpal involvement (p); ulceration (u), fistula ( $f$ ) and abscess (a); RMSEA: Root Mean Squared Error of Approximation; SOHO-5: Scale of Oral Health Outcomes for 5-year-old children; SPSS: Statistical Package for Social Sciences; TLI: Tucker Lewis Index; WHO: World Health Organisation
} 


\section{Acknowledgements}

The authors acknowledge with many thanks the help of kindergarten's staffs and all respondents who participated in this research.

\section{Authors' contributions}

RJ contributed in the study design, interpretation of data and writing the manuscript. RJJ was involved in the design of the study, data acquisition, and reviewed the manuscript. RN involved in the study design, data analysis and interpretation, and reviewed the manuscript. The author(s) read and approved the final manuscript.

\section{Funding}

The study had not been funded.

\section{Availability of data and materials} Yes.

\section{Ethics approval and consent to participate}

The study obtained the agreement of the Ethics Committee of the Ministry of Health under number 34-MSANP/CE of 17 March 2015 and verbal consent of the participants.

\section{Consent for publication}

All authors have read the manuscript and approved the submission.

\section{Competing interests}

The authors declare that they have no competing interests.

\section{Author details}

${ }^{1}$ IOSTM/University of Mahajanga, Mahajanga, Madagascar. ${ }^{2}$ EDNES/University of Mahajanga, Mahajanga, Madagascar. ${ }^{3}$ University Paris Diderot, Paris, France.

Received: 30 October 2017 Accepted: 12 February 2020

Published online: 24 February 2020

\section{References}

1. Locker D, Allen F. What do measures of 'oral health-related quality of life' measure? Community Dent Oral Epidemiol. 2007;35(6):401-11.

2. Sischo L, Broder HL. Oral Health-related Quality of Life: What, Why, How, and Future Implications. J Dent Res. 2011;90(11):1264-70. https://doi.org/10. $1177 / 0022034511399918$

3. WHOQOL Group. The World Health Organization Quality of Life assessment (WHOQOL): position paper from the World Health Organization. Soc Sci Med. 1995;41(10):1403-9.

4. Bennadi D, Reddy CV. Oral health related quality of life. J Int Soc Prev Community Dent. 2013;3:1-6.

5. Jokovic A, Locker D, Stephens M, Kenny D, Tompson B, Guyatt G. Validity and reliability of a questionnaire for measuring child oral-health-related quality of life. J Dent Res. 2002;81(7):459-63 PubMed.

6. Jokovic A, Locker D, Tompson B, Guyatt G. Questionnaire for measuring oral health-related quality of life in eight- to ten-year-old children. Pediatr Dent. 2004;26(6):512-8 PubMed.

7. Jokovic A, Locker D, Guyatt G. Short forms of the Child Perceptions Questionnaire for 11-14-year-old children (CPQ11-14): development and initial evaluation. Health Qual Life Outcomes. 2006;4:4.

8. Gherunpong S, Tsakos G, Sheiham A. Developing and evaluating an ora health-related quality of life index for children; the CHILD-OIDP. Community Dent Health. 2004:21(2):161-9.

9. Broder HL, McGrath C, Cisneros GJ. Questionnaire development: face validity and item impact testing of the child Oral health impact profile. Community Dent Oral Epidemiol. 2007;35:8-19.

10. Huntington NL, Spetter D, Jones JA, Rich SE, Garcia Rl, Spiro A 3rd. Development and validation of a measure of pediatric oral health-related quality of life: the POQL. J Public Health Dent. 2011;71(3):185-93.

11. Filstrup SL, Briskie D, da Fonseca M, Lawrence L, Wandera A, Inglehart MR. Early childhood caries and quality of life: child and parent perspectives. Pediatr Dent. 2003:25(5):431-40

12. Tsakos G, Blair YI, Yusuf H, Wright W, Watt RG, Macpherson LM. Developing a new self-reported scale of oral health outcomes for 5-year-old children (SOHO-5). Health Qual Life Outcomes. 2012;10:62.
13. Pahel BT, Rozier RG, Slade GD. Parental perceptions of children's Oral health: the early childhood oral health impact scale (ECOHIS). Health Qual Life Outcomes. 2007;5:6.

14. Li S, Veronneau J, Allison PJ. Validation of a French language version of the early childhood oral health impact scale (ECOHIS). Health Qual Life Outcomes. 2008;6:9.

15. Lee GH, McGrath C, Yiu CK, King NM. Translation and validation of a Chinese language version of the early childhood oral health impact scale (ECOHIS). Int J Paediatr Dent. 2009:19:399-405.

16. Jabarifar SE, Golkari A, ljadi MH, Jafarzadeh M, Khadem P. Validation of a Farsi version of the early childhood oral health impact scale (F-ECOHIS). BMC Oral Health. 2010;10:4.

17. Scarpelli AC, Oliveira BH, Tesch FC, Leão AT, Pordeus IA, Paiva SM. Psychometric properties of the Brazilian version of the early childhood Oral health impact scale (B-ECOHIS). BMC Oral Health. 2011;11:19.

18. Peker K, Uysal Ö, Bermek G. Cross - cultural adaptation and preliminary validation of the Turkish version of the early childhood oral health impact scale among 5-6-year-old children. Health Qual Life Outcomes. 2011;9:118.

19. Bordoni N, Ciaravino O, Zambrano O, Villena R, Beltran-Aquilar E, Squassi A. Early childhood oral health impact scale (ECOHIS), translation and validation in Spanish language. Acta Odontol Latinoam. 2012;25(3):270-8.

20. Jankauskienè B, Narbutaite J, Kubilius R, Gleiznys A. Adaptation and validation of the early childhood oral health impact scale in Lithuania. Stomatologija, Baltic Dental and Maxillofacial J. 2012;14:108-13.

21. Kulturolosko-Lingvisticko, et al. Translation and cross-cultural adaptation of the instrument for the oral health-related quality of Life in 3 to 5 years old children in Bosnia-Herzegovina. Stomatoloski Vjesnik. 2012;2:107-12.

22. López Ramos RP, García Rupaya CR, Villena-Sarmiento R, Bordon NE. Cross cultural adaptation and validation of the early childhood health impact scale (ECOHIS) in Peruvian preschoolers. Acta Odontol Latinoam. 2013;26(2):60-7.

23. Hashim AN, Yusof ZY, Esa R. The Malay version of the Early Childhood Oral Health Impact Scale (Malay-ECOHIS)--assessing validity and reliability. Health Qual Life Outcomes. 2015;25(13):190.

24. Riaz FM, Faisal J, Benish M. Translation, cross-cultural adaptation and validation of early childhood oral health impact scale (ECOHIS) in Urdu. Int Dent Health Sci. 2016;3(2):294-301.

25. Petersen PE, Razanamihaja N. Oral health status of children and adults in Madagascar. Int Dent J. 1996:46:41-7.

26. World Health Organisation. Oral Health Surveys. Basic methods. 4th ed. Geneva: World Health Organisation; 1997.

27. Monse B, Heinrich-Weltzien R, Benzian H, Holmgren C, van Palenstein Helderman W. PUFA--an index of clinical consequences of untreated dental caries. Community Dent Oral Epidemiol. 2010;38(1):77-82.

28. Beaton DE, Bombardier C, Guillemin F, Ferraz MB. Guidelines for the process of cross-cultural adaptation of self-report measures. Spine. 2000;25(24):3186-91.

29. Guillemin F, Bombardier C, Beaton D. Cross cultural adaptation of healthrelated quality of life measures: literature and proposed quidelines. J Clin Epidemiol. 1993;46:1417-32.

30. Shrout PE, Fleiss JL. Intraclass correlations: uses in assessing rater reliability. Psychol Bull. 1979;86:420-8.

31. Egree JC, Berstein IH. Psychometric theory. New York: McGraw-Hill; 1994

32. Waltz CF, Strickland OL, Lenz ER. Measurement in nursing and health research. 3rd ed. New York: Springer; 2005.

33. Cronbach L. Coefficient alpha and internal structure of tests. Psychometrika. 2006;16:297-333.

34. DeVon H, Block M, Moyle-Wright P, Ernst D, Hayden S, Lazzara D, Savoy S, Kostas-Polston E. A psychometric toolbox for testing validity and reliability. J Nurs Scholarsh. 2007:39:155-64.

35. Nunnally JC, Berstein IH. Psychometric theory. New York: McGraw-Hill; 1994.

36. Kaiser HF. An index of factorial simplicity. Psychometrika. 1974;39:31-6.

37. Bentler PM, Bonett DG. Significance tests and goodness-of-fit in the analysis of covariance structures. Psych Bull. 1980;88:588-600.

38. Tucker $L R$, Lewis $C$. A reliability coefficient for maximum likelihood factor analysis. Psychometrika. 1973;38:1-10 Google Scholar, Crossref.

39. Bollen. Structural equations with latent variables. New York: Wiley; 1989.

40. Cohen J. Statistical power analysis for the behavioural sciences. 2nd ed. Hillsdale: Lawrence Erlbaum and Associates; 1988.

41. Terwee $\mathrm{CB}$, Bot SDM, de Boer MR, van der Windt DAWM, Knol DL, Dekker J, Bouter LM, de Vet HCW. Quality criteria were proposed for measurement properties of health status questionnaires. J Clin Epidemiol. 2007;60(1):34-42. 
42. Clark LA, Watson D. Constructing validity: basic issues in scale development. Psychol Assess. 1995;7(3):309-19.

43. Anthoine $E$, Moret L, Regnault A, et al. Sample size used to validate a scale: a review of publications on newly -developed patient report outcomes measures. Health Qual Life Outcomes. 2014;12:176.

44. Dak-Albab RJ, Dashash MA. The influence of socioeconomic status on oral health-related quality of life among Syrian children with cleft lip, or palate, or both. Saudi Med J. 2013;34(2):181-6.

45. Hu L, Bentler PM. Cut-off criteria for fit indexes in covariance structure analysis: conventional criteria versus alternatives. Struct Equ Model. 1999; 6(1):1-55.

46. Tabachnick BG, Fidell LS. Using multivariate statistics. 4th ed. New York: Harper Collins; 2001

47. Guadagnoli E, Velicer WF. Relation of sample size to the stability of component patterns. Psychol Bull. 1988;103(2):265-75.

\section{Publisher's Note}

Springer Nature remains neutral with regard to jurisdictional claims in published maps and institutional affiliations.

Ready to submit your research? Choose BMC and benefit from:

- fast, convenient online submission

- thorough peer review by experienced researchers in your field

- rapid publication on acceptance

- support for research data, including large and complex data types

- gold Open Access which fosters wider collaboration and increased citations

- maximum visibility for your research: over $100 \mathrm{M}$ website views per year

At $\mathrm{BMC}$, research is always in progress.

Learn more biomedcentral.com/submissions 